\title{
Evaluating the Effect of Flow and Interface Type on Pressures Delivered With Bubble CPAP in a Simulated Model
}

\author{
Stephanie A Bailes RRT-NPS NREMT-B, Kimberly S Firestone MSc RRT, \\ Diane K Dunn RRT-NPS, Neil L McNinch MSc RN, Miraides F Brown MSc, and \\ Teresa A Volsko MHHS RRT FAARC
}

\begin{abstract}
BACKGROUND: Bubble CPAP, used for spontaneously breathing infants to avoid intubation or postextubation support, can be delivered with different interface types. This study compared the effect that interfaces had on CPAP delivery. We hypothesized that there would be no difference between set and measured levels between interface types. METHODS: A validated preterm infant nasal airway model was attached to the ASL 5000 breathing simulator. The simulator was programmed to deliver active breathing of a surfactant-deficient premature infant with breathing frequency at $70 \mathrm{breaths} / \mathrm{min}$ inspiratory time of $0.30 \mathrm{~s}$, resistance of $150 \mathrm{~cm} \mathrm{H}_{2} \mathrm{O} / \mathrm{L} / \mathrm{s}$, compliance of $0.5 \mathrm{~mL} / \mathrm{cm} \mathrm{H}_{2} \mathrm{O}$, tidal volume of $5 \mathrm{~mL}$, and esophageal pressure of $-10 \mathrm{~cm} \mathrm{H}_{2} \mathrm{O}$. Nasal CPAP prongs, size 4030, newborn and infant RAM cannulas were connected to a nasal airway model and a bubble CPAP system. CPAP levels were set at 4, 5, 6, 7, 8, and $9 \mathrm{~cm} \mathrm{H}_{2} \mathrm{O}$ with flows of 6, 8, and $10 \mathrm{~L} / \mathrm{min}$ each. Measurements were recorded after $1 \mathrm{~min}$ of stabilization. The analysis was performed using SAS 9.4. The Kolmogorov-Smirnov test assessed normality of the data. The Friedman test was used to compare non-normally distributed repeated measures. The Wilcoxon signed-rank test was used to conduct post hoc analysis. All tests were 2 -sided, and $P$ values of $<.05$ were considered as indicating significant differences unless otherwise indicated. RESULTS: At lower set CPAP levels, 4-6 cm $\mathrm{H}_{2} \mathrm{O}$, measured CPAP dropped precipitously with the nasal prongs with the highest flow setting. At higher CPAP levels, 7-9 cm $\mathrm{H}_{2} \mathrm{O}$ measured CPAP concomitantly increased as the flow setting increased. Statistically significant differences in set and measured CPAP occurred for all devices across all CPAP levels, with the measured CPAP less than set for all conditions, $P<.001$. CONCLUSIONS: Set flow had a profound effect on measured CPAP. The concomitant drop in measured pressure with high and low flows could be attributed to increased resistance to spontaneous breathing or insufficient flow to meet inspiratory demand. Clinicians should be aware of the effect that the interface and flow have on CPAP delivery. Key words: bubble CPAP; respiratory distress syndrome; noninvasive ventilation; lung model; nasal prongs; flow dependence. [Respir Care 2016;61(3):333-339. (C) 2016 Daedalus Enterprises]
\end{abstract}

Introduction

The literature supports the use of bubble CPAP as an alternative mode of respiratory management instead of

\footnotetext{
Ms Bailes is affiliated with the Simulation Center of Safety and Reliability, Ms Firestone is affiliated with the Neonatology Department, Ms Dunn is affiliated with the Department of Respiratory Care, Mr McNinch and Ms Brown are affiliated with the Rebecca D Considine Research Institute, and Ms Volsko is affiliated with Nursing Administration, Akron Children's Hospital, Akron, Ohio. Correspondence: Teresa A Volsko MHHS RRT FAARC. E-mail: tvolsko@chmca.org.
}

DOI: $10.4187 /$ respcare. 04251 routine intubation and surfactant administration for spontaneously breathing preterm infants ${ }^{1}$ and as a primary mode of respiratory management for spontaneously breathing infants born at 26-29 weeks gestation who are admitted to a neonatal ICU for respiratory distress. ${ }^{2,3}$ The Vermont Oxford Group reports that CPAP started soon after birth is a strategy that reduces bronchopulmonary dysplasia and death while not showing any increased risk of adverse outcomes from delaying or eliminating surfactant administration. ${ }^{3}$ In practice, bubble CPAP is commonly used initially as an inexpensive noninvasive mode of respiratory support that maintains lung volume to avoid intubation or for postextubation support. ${ }^{4}$ 
CPAP has been used as an intervention for infants experiencing respiratory distress for several decades. Initially, application of CPAP for the newborn was by an endotracheal tube or face mask, with nasal prongs being first introduced in 1973.4,5 A variety of interfaces are now available to connect the patient with the bubble CPAP unit. The interfaces differ in design and in their naris/prong ratio. The literature reports that prong occlusion of the nares of $>50 \%$ is required to maintain a CPAP effect. ${ }^{6}$ Some devices, such as nasal CPAP prongs (Fisher \& Paykel, Auckland, New Zealand) are designed to fit securely in the nares and have a minimal leak at the interface when correctly fitted. There are devices, such as the RAM cannula (Neotech, Valencia, California), that may be used with CPAP systems. The manufacturer recommendation for prong occlusion is $60-80 \%$ of the naris space. ${ }^{7}$

Just as there are many options for CPAP interfaces, there are several types of bubble CPAP systems that are commercially available. We chose to evaluate 3 interface types, specifically the Fisher \& Paykel CPAP prongs and the infant and newborn RAM cannulas with one specific closed bubble CPAP system, the Babi-Plus bubble CPAP system (Respiralogics, San Marcos, California). We evaluated the interfaces and bubble CPAP system that were germane to each of our 4 Level 3 neonatal ICUs across our health system. The Babi-Plus bubble CPAP system was selected because this device was closed and self-contained and could be easily secured during transport for an institution whose admissions to the neonatal ICU are all outborn.

It is important for clinicians to have a working knowledge of the CPAP system and to understand the effect that the interface has on CPAP delivery in order to optimize therapy. Therefore, we used a simulated lung model to evaluate the 3 interfaces used in our neonatal ICUs to determine the effect that the patient interface had with bubble CPAP administration. We hypothesized that there would be no significant difference between set and measured CPAP levels when different interfaces, specifically nasal CPAP prongs and the RAM cannula, were used with a bubble CPAP system.

\section{Methods}

\section{Lung Model}

The ASL 5000 simulator (IngMar Medical, Pittsburgh, Pennsylvania) was programmed to simulate the pulmonary mechanics of an actively breathing 28 -week gestation, surfactant-deficient infant. Resistance was set at $150 \mathrm{~cm}$ $\mathrm{H}_{2} \mathrm{O} / \mathrm{L} / \mathrm{s}$, and compliance was set at $0.5 \mathrm{~mL} / \mathrm{cm} \mathrm{H}_{2} \mathrm{O}$. The active breathing model had a set breathing frequency of 70 breaths/min, an inspiratory time of $0.30 \mathrm{~s},{ }^{8,9}$ and a

\section{QUICK LOOK}

\section{Current knowledge}

Bubble CPAP is frequently used in the neonatal ICU to avoid intubation or as postextubation support for spontaneously breathing infants experiencing respiratory distress. When nasal interfaces are used, a prong occlusion of the naris of $>50 \%$ is required to maintain a CPAP effect to compensate for inherent variable leaks. Continuous flow delivered through the system may also affect CPAP delivery. However, the interaction between the flow delivered through the system, interface type, and leak has not been well documented in the literature.

\section{What this paper contributes to our knowledge}

The flow setting through a bubble CPAP system had a profound but unpredictable effect on measured CPAP level. Depending on the setting, flow can increase resistance to spontaneous breathing or fail to meet inspiratory demands. Since delivered CPAP levels are not typically measured with bubble CPAP systems, clinicians need to be aware of the effect not only of the interface but also of flow on CPAP delivery.

simulated esophageal pressure of $-10 \mathrm{~cm} \mathrm{H}_{2} \mathrm{O}^{8,9}$ to yield a tidal volume of $5 \mathrm{~mL}$.

\section{Nasal Airway Model}

A validated anatomically correct physical model ${ }^{8}$ of a preterm infant nasal airway was attached to a 3-inch foam craft ball. The exterior of the ball was covered with Tegaderm with an additional layer of Duoderm on the lateral aspects to create a facial model that facilitated the securement of the 25-29-cm Fisher \& Paykel bonnet. The facial model provided a 3-dimensional surface with which the Fisher \& Paykel size 4030 nasal prongs/bonnet assembly (Fisher \& Paykel, Auckland, New Zealand) (Fig. 1) and the newborn and infant-sized RAM cannulas were secured (Neotech, Valencia, California). Naris and prong measurements were obtained by a digital caliper. The percentage of naris space that the prongs occluded was calculated for each device used (Table 1). The Fisher \& Paykel size 4030 nasal prongs and newborn-sized RAM cannula represented the devices that were sized appropriately per manufacturer recommendations for the naris size. The infant-sized RAM cannula represented a device that is larger than the manufacturer recommendations for use but in clinical practice may be used to provide a tighter seal between the prongs and the nares to minimize the amount of leak and, theoretically, pressure loss at the patient interface. 
Each interface was attached to the facial model ${ }^{8}$ in accordance with manufacturer recommendations. Specifically, the Fisher \& Paykel prongs were affixed to the bonnet and the nasal tubing (Fig. 2). The RAM cannula tubing was secured to the lateral aspects of the facial model, with the lasso secured near the base of the model's occiput, mimicking the technique recommended by the manufacturer (Fig. 2).

\section{Simulator/Bubble CPAP System Interface}

Bubble CPAP was provided by the Babi-Plus bubble CPAP system. Six CPAP levels at 3 different flows were tested. Specifically, CPAP levels of $4,5,6,7,8$, and $9 \mathrm{~cm} \mathrm{H}_{2} \mathrm{O}$ were tested with flows of 6,8 , and $10 \mathrm{~L} / \mathrm{min}$ for each.

Each combination of CPAP level and flow was tested with each of the interfaces, the Fisher \& Paykel size 4030, newborn and infant-sized RAM cannulas connected to the nasal airway model ${ }^{8}$ and the Babi-Plus bubble CPAP system.

\section{Data Collection and Analysis}

Before collecting data, a 1-min stabilization period was observed. Data were electronically collected for a 2-min period and were recorded following the 1-min stabilization period. Airway pressure $\left(\mathrm{cm} \mathrm{H}_{2} \mathrm{O}\right)$ was electronically recorded by the ASL 5000 simulator on 40 consecutive breaths for each experimental condition. Pressures were

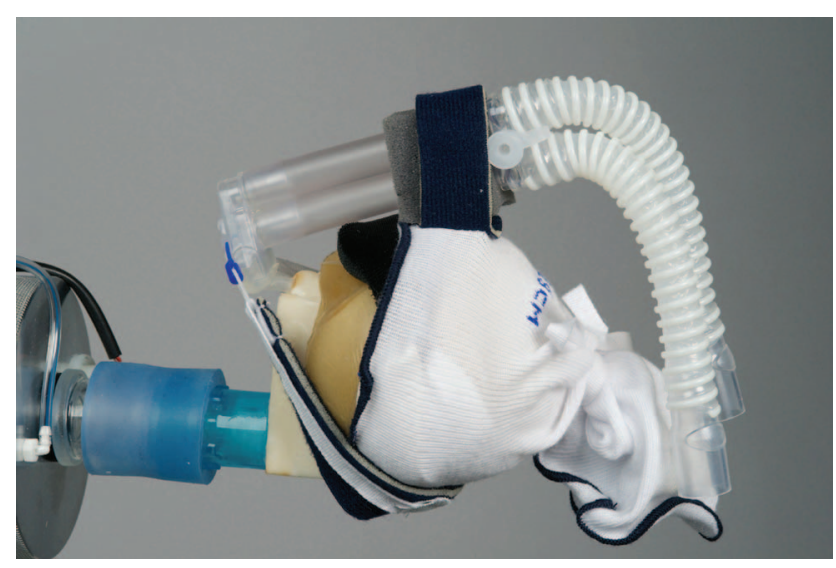

Fig. 1. Validated nasal model attached to the foam craft ball to construct a physical model with which a size 25-29-cm Fisher \& Paykel bonnet would snugly fit. measured internally by the lung simulator rather than using an external device to measure pressure. The ASL 5000 uses the terminology "mouth pressure" to designate pressures recorded by the simulator. Data from the postanalysis software were exported from the ASL 5000 into Excel (Microsoft, Redmond, Washington) and analyzed in SAS 9.4 (SAS Institute, Cary, North Carolina).

Descriptive statistics were used to report the bubble effect, or amplitude, across the range of flows and pressures. Each breath within an individual experimental condition represented one iteration, with 40 repeated measures obtained. The Kolmogorov-Smirnov test assessed normality of the data before hypothesis testing. The Friedman test compared non-normally distributed repeated measures of measured pressure between each combination of interface type and flow setting, and the Wilcoxon signed-rank test was used to conduct post hoc analysis, evaluated with Hochberg-corrected $\alpha$. All tests were 2-sided and evaluated with the type- 1 error rate of $\alpha$ equal to a .05 level of statistical significance.

\section{Results}

At lower set CPAP levels, 4-6 $\mathrm{cm} \mathrm{H}_{2} \mathrm{O}$, the measured CPAP level precipitously dropped with the Fisher \& Paykel nasal prongs with the highest $(10 \mathrm{~L} / \mathrm{min})$ flow setting. At higher CPAP levels, 7-9 $\mathrm{cm} \mathrm{H}_{2} \mathrm{O}$, there was a concomitant increase in measured CPAP levels as flow setting increased. The Friedman test indicated that there was a statistically significant difference in set and measured CPAP levels for all devices across all CPAP levels, with the measured CPAP levels less than set for all conditions, $P<.001$ (Fig. $3)$. The highest median measured pressure was observed at a set pressure of $4 \mathrm{~cm} \mathrm{H}_{2} \mathrm{O}$ with the Fisher \& Paykel prongs at a flow of $8 \mathrm{~L} / \mathrm{min}$ (Fig. 3). The lowest absolute median difference in measured pressure was found at a set pressure of $4 \mathrm{~cm} \mathrm{H}_{2} \mathrm{O}$ with the RAM newborn at a flow of 6 and $10 \mathrm{~L} / \mathrm{min}$ and at a set pressure of $4 \mathrm{~cm} \mathrm{H}_{2} \mathrm{O}$ with the RAM infant at a flow of 8 and $10 \mathrm{~L} / \mathrm{min}$. Pairwise analysis demonstrated statistically significant differences between set and measured pressures with 31 of 36 combinations $(86 \%)$ of interface types and flows (Table 2).

The RAM cannula size (newborn RAM cannula) recommended by the manufacturer for the naris model delivered slightly less than half of the set pressure across all of

Table 1. Right and Left Nares and Prong Measurements and Percent Nares Occlusion for Each of the Devices Tested

\begin{tabular}{llcc}
\hline \hline $\begin{array}{c}\text { Naris Measurement } \\
\text { of Model }\end{array}$ & $\begin{array}{c}\text { Newborn RAM } \\
\text { Prong Measurement } \\
\text { (Percent Occlusion) }\end{array}$ & $\begin{array}{c}\text { Infant RAM } \\
\text { Prong Measurement } \\
\text { (Percent Occlusion) }\end{array}$ & $\begin{array}{c}\text { Fisher \& Paykel 4030 } \\
\text { Prong Measurement } \\
\text { (Percent Occlusion) }\end{array}$ \\
\hline $\begin{array}{l}\text { Left naris } 5.08 \mathrm{~mm} \\
\text { Right naris } 5.30 \mathrm{~mm}\end{array}$ & Left prong 3.99 mm (78\%) & Left prong $4.23 \mathrm{~mm} \mathrm{(83 \% )}$ & $\begin{array}{c}\text { Left prong 3.85 mm (76\%) } \\
\text { Right prong 3.85 mm (73\%) }\end{array}$ \\
\hline
\end{tabular}




\section{EFFect of Flow and Interface on Bubble CPAP Pressures}
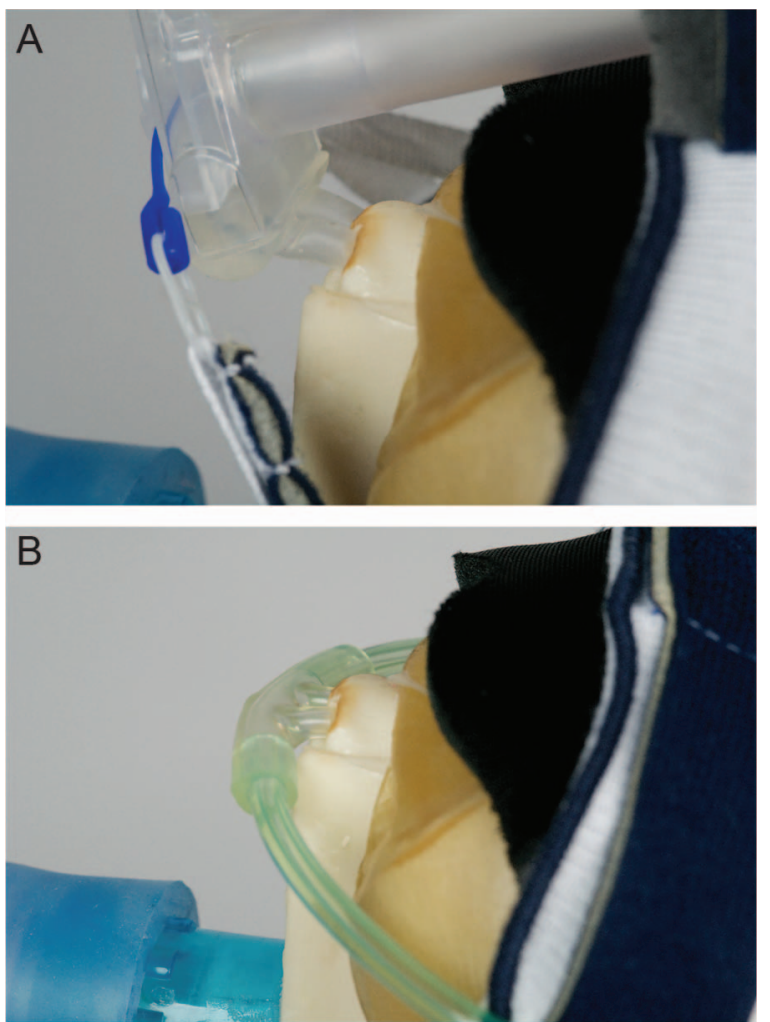

Fig. 2. Illustration of the interfaces attached to the physical model and lung simulator. A: Fisher \& Paykel nasal prongs secured with bonnet. B: Infant-sized RAM cannulas connected to the nasal airway model. The bonnet was left in place to verify that the model's head circumference did not change with the different interfaces tested.

the pressure settings tested across the range of flows (Table 3). The infant RAM cannula, one size larger than recommended by the manufacturer for the naris size, delivered approximately half of the set pressure. The interface with the largest naris occlusion delivered approximately $60 \%$ of the set pressure.

\section{Discussion}

Our results confirm that the measured CPAP levels, when compared with set CPAP levels, across the range of flows were maintained more often with the Fisher \& Paykel nasal prongs compared with the RAM cannula when each interface was sized appropriately according to manufacturer recommendations.

Although there are many bubble CPAP delivery systems available, the Babi-Plus was used in this investigation because it was germane to our institution for in-patient care and during interfaculty air/ground transport. This system is a closed water bubble CPAP system, which prevents large fluctuations in the CPAP level when the system may experience movement that naturally occurs during patient care or transport. ${ }^{10}$
The use of the Babi-Plus in this investigation controlled for a confounding variable, specifically variations in CPAP attributed to how the bubble CPAP delivery system functions. This particular device incorporates a baffle/diffuser to provide a more constant CPAP delivery, despite the oscillatory effect of the bubbling system. ${ }^{10}$ Since this device does not deliver wide variations of CPAP, the measured delivered CPAP levels were relatively stable, and differences between set and measured CPAP levels delivered to the lung model were more reflective of the type of interface used rather that the combination of the system and the interface. This system also incorporates a pressure relief value to minimize the propensity of delivering excessive pressures that can contribute to overdistention and lung injury.

When the percentage of nares occlusion was compared, there was no appreciable difference in the percent occlusion from the manufacturer-recommended prong size for the Fisher \& Paykel nasal prongs or RAM cannula. Poli et al ${ }^{10}$ reported that the delivery of a set level of CPAP was also dependent on the percentage of the nares, the CPAP device occluded. Early published data suggest that a tighter seal between the oxygen delivery system and the nose is essential, which presumably results in higher CPAP pressure for a given oxygen flow and ventilatory pattern. ${ }^{11}$ The airway pressure generated with high-flow oxygen therapy is variable and unpredictable. ${ }^{11,12}$ The use of a tighter seal would increase the propensity for complications such as nasal obstruction, bleeding, and necrosis, which the literature reports are associated with the use of oxygen delivery via nasal cannula. ${ }^{13,14}$ Therefore, clinical practice dictates that the nasal prongs be sized so as not to completely occlude the nares, therefore always maintaining a leak in the system. ${ }^{15}$ Our results demonstrate that even with a tighter seal through the use of an interface that reduces the leak, such as the use of the infant RAM cannula in this model, the delivered CPAP level was not appreciably different from when the manufacturer-recommended prong size was used.

The therapeutic effectiveness of CPAP is in part dependent on the ability to achieve and maintain a constant distending pressure. Flow to the model through the device was incrementally increased to compensate for the pressure loss through the leak. Flow was increased in this experiment to mimic what may occur clinically to meet the perceived inspiratory demands of the patient and compensate for leak. Since bubble CPAP systems have no capabilities to monitor or reflect patient flow requirement, flow titration is performed blindly. Our data indicate that when flow was increased through the system at lower set CPAP levels, 4-6 $\mathrm{cm} \mathrm{H}_{2} \mathrm{O}$, the measured CPAP level precipitously dropped with the Fisher \& Pakyel 4030 nasal prongs with the highest flow setting, $10 \mathrm{~L} / \mathrm{min}$. At higher CPAP levels, 7-9 $\mathrm{cm} \mathrm{H}_{2} \mathrm{O}$, there was a concomitant increase in measured CPAP levels as the flow setting increased, but this increase was unpredictable and different with each 


\section{EFFect of Flow ANd InTerface on BubBle CPAP PRESSURes}
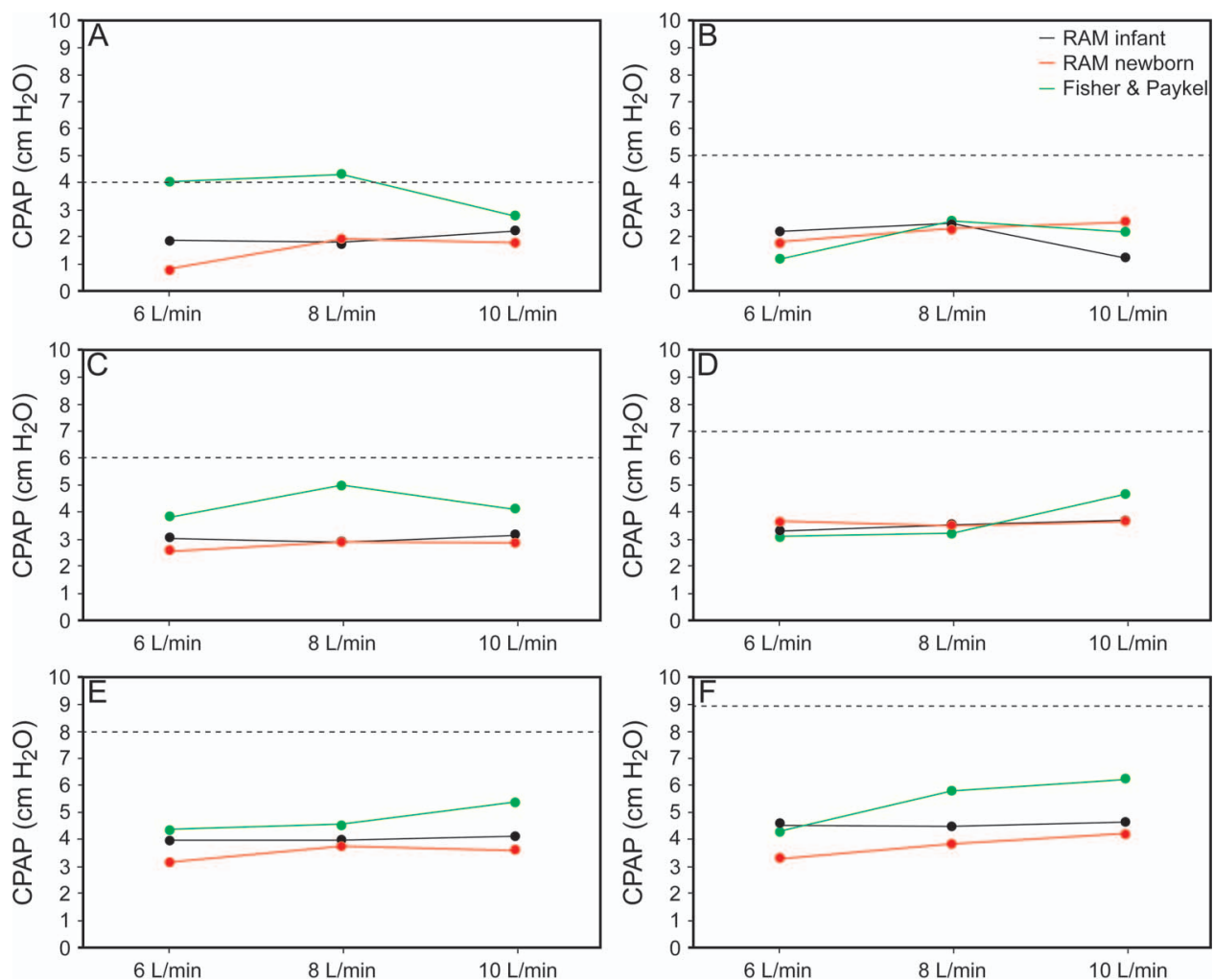

Fig. 3. Device comparison of measured median CPAP levels for each set CPAP level across the range of flows. Dotted lines denote the set CPAP in each scenario. $P<.001$ in all cases.

device used. There was a statistically significant difference between set and measured CPAP levels for all devices across all CPAP levels, with the measured CPAP level less than set for all experimental conditions. This interaction may be explained by Poiseulle's law, which states that the velocity of the steady flow through a narrow tube varies directly with the pressure and the 4th power of the radius of the tube and inversely with the length of the tube and the coefficient of viscosity. ${ }^{16}$ When leaks are present due to interface fit for the delivery of nasal CPAP, the flow will follow the path of least resistance. To compensate for a drop in pressure due to leak, the respiratory therapist may be tempted to increase the flow rate, which could lead to turbulent flow within the small diameter of the CPAP interface. The airways of infants and children are smaller in diameter and contribute to increased airways resistance due to their anatomical features. The compounding effect of turbulent flow through the small internal lumen of the CPAP interface, the anatomical features of children, and increased airway resistance and decreased lung compliance inherent to respiratory distress of the newborn contribute to the variable and unpredictable drop in CPAP pressure.

Unlike CPAP delivery through a mechanical ventilator, bubble CPAP systems do not have the ability to provide variable flow or feedback on delivered CPAP pressures at the nares. Therefore, the clinician does not have an objective means to monitor the effect that adjustments to constant flow or interface type and fit have on the CPAP delivered to the patient. Clinical studies demonstrate increased work of breathing with constant flow CPAP systems compared with CPAP systems with variable flow capabilities. ${ }^{17}$ Increasing the constant flow through a system with increased resistance may further encumber breathing. It is important for the respiratory therapist to understand the type of bubble CPAP system that is used and the effect that leak has on delivered pressures. The use of a tighter seal did not result in an improvement in delivered CPAP levels. These results were similar to those reported by Poli et al, ${ }^{10}$ where the prongs fit tightly in the nares and did not allow for a leak. However, the risk associated with a tight seal far outweighs the clinical benefit by increasing the propensity for skin breakdown. ${ }^{12}$ Iyer et al ${ }^{18}$ have shown in an ex vivo experimental design with a lung simulator that the appropriate size interface is imperative: When the cannula size was too small relative to the nasal model diameter, pressure transmission was significantly reduced, resulting in a minimal amount of pressure being applied to the model.

Our data confirm that the interaction between flow and delivered pressure is unpredictable. Increasing flow on a set CPAP of $5 \mathrm{~cm} \mathrm{H}_{2} \mathrm{O}$ with the infant RAM cannula 


\section{EFFect of Flow and Interface on Bubble CPAP Pressures}

Table 2. Multiple-Comparison Post Hoc Analysis of the Effect of Interface Type and Flow on Measured Pressure

\begin{tabular}{|c|c|c|c|}
\hline Interface and Flow Combination & Median Difference & $P$ & Hochberg Threshold \\
\hline RAM newborn, flow 6 vs RAM newborn, flow 8 & -0.0248 & .88 & 0.0500 \\
\hline RAM newborn, flow 8 vs RAM newborn, flow 10 & 0.0473 & .50 & 0.0250 \\
\hline RAM newborn, flow 6 vs RAM newborn, flow 10 & 0.0153 & .49 & 0.0167 \\
\hline RAM infant, flow 8 vs RAM newborn, flow 8 & -0.0587 & .056 & 0.0125 \\
\hline RAM infant, flow 8 vs RAM newborn, flow 10 & -0.0755 & .043 & 0.0100 \\
\hline RAM newborn, flow 6 vs RAM infant, flow 6 & 1.6007 & $<.001$ & 0.0083 \\
\hline RAM newborn, flow 6 vs Fisher \& Paykel, flow 6 & -2.1687 & $<.001$ & 0.0071 \\
\hline RAM newborn, flow 6 vs RAM infant, flow 8 & 0.0553 & $<.001$ & 0.0063 \\
\hline RAM newborn, flow 6 vs Fisher \& Paykel, flow 8 & -2.4613 & $<.001$ & 0.0056 \\
\hline RAM newborn, flow 6 vs RAM infant, flow 10 & -0.3430 & $<.001$ & 0.0050 \\
\hline RAM newborn, flow 6 vs Fisher \& Paykel, flow 10 & -0.9686 & $<.001$ & 0.0045 \\
\hline RAM infant, flow 6 vs Fisher \& Paykel, flow 6 & -3.8411 & $<.001$ & 0.0042 \\
\hline RAM infant, flow 6 vs RAM infant, flow 8 & -1.5469 & $<.001$ & 0.0038 \\
\hline RAM infant, flow 6 vs RAM newborn, flow 8 & -1.5305 & $<.001$ & 0.0036 \\
\hline RAM infant, flow 6 vs Fisher \& Paykel, flow 8 & -4.1081 & $<.001$ & 0.0033 \\
\hline RAM infant, flow 6 vs RAM infant, flow 10 & -1.9562 & $<.001$ & 0.0031 \\
\hline RAM infant, flow 6 vs RAM newborn, flow 10 & -1.6613 & $<.001$ & 0.0029 \\
\hline RAM infant, flow 6 vs Fisher \& Paykel, flow 10 & -2.6173 & $<.001$ & 0.0028 \\
\hline Fisher \& Paykel, flow 6 vs RAM infant, flow 8 & 2.2522 & $<.001$ & 0.0026 \\
\hline Fisher \& Paykel, flow 6 vs RAM newborn, flow 8 & 2.2255 & $<.001$ & 0.0025 \\
\hline Fisher \& Paykel, flow 6 vs Fisher \& Paykel, flow 8 & -0.1637 & $<.001$ & 0.0024 \\
\hline Fisher \& Paykel, flow 6 vs. RAM infant, flow 10 & 1.8891 & $<.001$ & 0.0023 \\
\hline Fisher \& Paykel, flow 6 vs RAM newborn, flow 10 & 2.2229 & $<.001$ & 0.0022 \\
\hline Fisher \& Paykel, flow 6 vs Fisher \& Paykel, flow 10 & 1.2394 & $<.001$ & 0.0021 \\
\hline RAM infant, flow 8 vs Fisher \& Paykel, flow 8 & -2.5395 & $<.001$ & 0.0020 \\
\hline RAM infant, flow 8 vs RAM infant, flow 10 & -0.4463 & $<.001$ & 0.0019 \\
\hline RAM infant, flow 8 vs Fisher \& Paykel, flow 10 & -1.0552 & $<.001$ & 0.0019 \\
\hline RAM newborn, flow 8 vs Fisher \& Paykel, flow 8 & -2.4571 & $<.001$ & 0.0018 \\
\hline RAM newborn, flow 8 vs RAM infant, flow 10 & -0.2876 & $<.001$ & 0.0017 \\
\hline RAM newborn, flow 8 vs Fisher \& Paykel, flow 10 & -1.0529 & $<.001$ & 0.0017 \\
\hline Fisher \& Paykel, flow 8 vs RAM infant, flow 10 & 2.1714 & $<.001$ & 0.0016 \\
\hline Fisher \& Paykel, flow 8 vs RAM newborn, flow 10 & 2.4659 & $<.001$ & 0.0016 \\
\hline Fisher \& Paykel, flow 8 vs Fisher \& Paykel, flow 10 & 1.5377 & $<.001$ & 0.0015 \\
\hline RAM Infant, flow 10 vs RAM newborn, flow 10 & 0.3418 & $<.001$ & 0.0015 \\
\hline RAM infant, flow 10 vs Fisher \& Paykel, flow 10 & -0.6386 & $<.001$ & 0.0014 \\
\hline RAM newborn, flow 10 vs Fisher \& Paykel, flow 10 & -0.9716 & $<.001$ & 0.0014 \\
\hline
\end{tabular}

interface with a larger lumen produced a drop in delivered pressure (Fig. 3). Since it is difficult to predict the affect that setting changes (flow and pressure) have on bubble CPAP delivery, it is imperative for respiratory therapists to use their clinical assessment skills and thoroughly evaluate patients' response to setting titrations. This may require therapists to spend additional time at the bedside evaluating small incremental changes to flow or set pressure and/or changes in the interface to optimize therapy.

There were limitations to this study. The evaluation was conducted using a rigid naris model in a simulated patient. By design, this ex vivo experiment experienced limitations similar to those reported in the literature with simulated physiological models. ${ }^{6}$ As with other models used in simulation, this model ${ }^{8}$ was unable to account for the leak that could be present at the mouth or leaks that could intermit- tently occur at the nares or the mouth during normal patient movement. The model was limited to only one type of patient and the associated pulmonary characteristics for that gestational age.

\section{Conclusions}

Flow setting had a profound but unpredictable effect on measured CPAP level. The concomitant drop in measured pressure with high and low flows could be attributed to increased resistance to spontaneous breathing or insufficient flow to meet inspiratory demand. Since delivered CPAP levels may not be measured with bubble CPAP systems, clinicians need to be aware of the effect not only of the interface but also of flow on CPAP delivery. 


\section{EFFect of Flow and Interface on Bubble CPAP Pressures}

Table 3. Comparison of Set with Delivered CPAP Levels $(n=120)$

\begin{tabular}{|c|c|c|c|c|c|c|}
\hline \multirow{2}{*}{ Device } & \multicolumn{6}{|c|}{ Set CPAP Level $\left(\mathrm{cm} \mathrm{H}_{2} \mathrm{O}\right)$} \\
\hline & 4 & 5 & 6 & 7 & 8 & 9 \\
\hline \multicolumn{7}{|l|}{ RAM infant } \\
\hline Median & 1.88 & 2.18 & 3.01 & 3.47 & 4.03 & 4.60 \\
\hline IQR & 0.48 & 1.08 & 0.49 & 0.32 & 0.59 & 0.47 \\
\hline Minimum & 1.44 & 1.03 & 2.25 & 3.02 & 3.27 & 3.77 \\
\hline Maximum & 2.65 & 3.00 & 3.86 & 4.24 & 4.67 & 5.15 \\
\hline \multicolumn{7}{|l|}{ RAM newborn } \\
\hline Median & 1.57 & 2.19 & 2.66 & 3.57 & 3.45 & 3.70 \\
\hline IQR & 1.09 & 0.71 & 0.60 & 0.45 & 0.67 & 0.81 \\
\hline Minimum & 0.58 & 1.60 & 1.89 & 2.81 & 2.53 & 2.71 \\
\hline Maximum & 2.59 & 3.22 & 3.73 & 4.24 & 4.13 & 4.82 \\
\hline \multicolumn{7}{|c|}{ Fisher \& Paykel 4030} \\
\hline Median & 4.02 & 4.22 & 4.23 & 3.28 & 4.74 & 5.74 \\
\hline IQR & 1.37 & 2.41 & 1.22 & 1.44 & 0.86 & 1.73 \\
\hline Minimum & 2.47 & 1.86 & 1.01 & 2.58 & 3.88 & 3.83 \\
\hline Maximum & 4.68 & 5.72 & 9.84 & 5.68 & 5.71 & 6.47 \\
\hline
\end{tabular}

\section{ACKNOWLEDGMENT}

We thank Ted Stevens, photographer/graphic designer at Akron Children's Hospital, for photographing and providing expert editing of the figures.

\section{REFERENCES}

1. SUPPORT Study Group of the Eunice Kennedy Shriver NICHD Neonatal Research Network, Finer NN, Carlo WA, Walsh MC, Rich W, Gantz MG, et al. Early CPAP versus surfactant in extremely preterm infants. N Engl J Med 2010;362(21):1970-1979.

2. Committee on Fetus and Newborn, American Academy of Pediatrics. Respiratory support in preterm infants at birth. American Academy of Pediatrics 2014;133(1):171-174.

3. Dunn MS, Kaempf J, de Klerk A, de Klerk R, Reilly M, Howard D, et al. Randomized trial comparing 3 approaches to the initial respiratory management of preterm neonates. Pediatrics 2011;128(5): e1069-e1076.

4. Diblasi RM. Nasal continuous positive airway pressure (CPAP) for the respiratory care of the newborn infant. Respir Care 2009;54(9): 1209-1235.

5. Kattwinkel J, Fleming D, Cha CC, Fanaroff AA, Klaus MH. A device for administration of continuous positive airway pressure by the nasal route. Pediatrics 1973;52(1):131-134.

6. Volsko TA, Fedor K, Amadei J, Chatburn RL. High flow through a nasal cannula and CPAP effect in a simulated infant model. Respir Care 2011;56(12):1893-1900.

7. Neotech Products. http://www.neotechproducts.com/site/wp-content/ uploads/2011/11/DFU-FAQ-Trifold2.pdf. Accessed November 7, 2014.

8. Youngquist TM, Richardson CP, Diblasi RM. Effects of condensate in the exhalation limb of neonatal circuits on airway pressure during bubble continuous positive airway pressure. Respir Care 2013;58(11):18401846.
9. Ahluwalia JS, Morley CJ, Mockridge JNA. Computerised determination of spontaneous inspiratory and expiratory times in premature neonates during intermittent positive pressure ventilation. II: Results from 20 babies. Arch Dis Child Fetal Neonatal Ed. 1994;71(3):F161F164.

10. Poli JA, Richardson CP, DiBlasi RM. Volume oscillations delivered to a lung model using 4 different bubble CPAP systems. Respir Care 2015;60(3):371-381

11. Lee KS, Dunn MS, Fenwick M, Shennan AT. A comparison of underwater bubble continuous positive airway pressure with ventilator-derived continuous positive airway pressure in premature neonates ready for extubation. Biol Neonate 1998;73(2):69-75.

12. Newnam KM, McGrath JM, Estes T, Jallo N, Salyer J, Bass WT. An integrative review of skin breakdown in the preterm infant associated with nasal continuous positive airway pressure. J Obstet Gynecol Neonatal Nurs. 2013;42(5):508-516.

13. Kopelman AE, Holbert D. Use of oxygen cannulas in extremely low birthweight infants is associated with mucosal trauma and bleeding, and possibly with conagulase-negative staphylococcal sepsis. J Perinatol 2003;23(2):94-97.

14. Kopelman A. Airway obstruction in two extremely low birthweight infants treated with oxygen cannulas. J Perinatol 2003;23(2):164-165.

15. Barrington KJ. Management of respiratory failure in the preterm infant. Minerva Pediat 2008;60(2):183-191.

16. Volsko TA. Measuring and monitoring pulmonary function. In: Volsko TA, Chatburn RL, El-Khatib MF, editors. Equipment for respiratory care. Burlington, Massachusetts: Jones \& Bartlett Learning; 2014:265.

17. Liptsen E, Aghai ZH, Pyon KH, Saslow JG, Nakhla T, Long J, et al Work of breathing during nasal continuous positive airway pressure in preterm infants: a comparison of bubble vs variable-flow devices. J Perinatol 2005;25(7):453-458.

18. Iyer NP, Chatburn R. Evaluation of a nasal cannula in noninvasive ventilation using a lung simulator. Respir Care 2015;60(4):508-512. 